\title{
TRAVEL AND TOURISM COMPETITIVENESS INDEX 2019- QUANTILE REGRESSION APPROACH ON 2nd SUB-INDEX
}

\author{
Eva Litavcová* \\ University of Prešov, \\ Faculty of Management \\ and Business, \\ Prešov, Slovakia \\ eva.litavcova@unipo.sk

\section{Juraj Síč} \\ Brno University of \\ Technology, Faculty of \\ Information Technology, \\ Brno, Czech Republic \\ sicjuraj@fit.vutbr.cz \\ * corresponding author
}

Received: November 2021

Revision: November 2021

Accepted: December 2021

\begin{abstract}
The aim of the paper is to examine how much four pillars of the Travel and Tourism Competitiveness Index (TTCI) sub-index "T\&T Policy and Enabling Conditions" contribute to the overall TTCI and ranking among 140 countries. To meet the goal, quantile regression has been used. Several findings were obtained by analysis. The first result shows that pillar Price Competitiveness has almost no effect on the overall TTCI score or TTCI rank in the considered model. Second, the most important pillars are Prioritization of Travel and Tourism and International Openness. Third, a comparison of the results of the multiple quantile regression analysis with the ordinary least squares showed that the results of the above methods differ significantly for Pillar Environmental Sustainability. On the lower quantile levels, this pillar does not significantly affect the ranking while at higher quantile levels it does. On the contrary, it affects the overall TTCI score in the opposite way. Another reason for using quantile regression is justified by the restrictive assumptions of OLS that it does not require. This paper contributes to the existing literature connected with tourism competitiveness. It can help reveal hidden multidimensional relationships between variables considered at different quantile levels, and thus can be a motivation for further improving the methods used to create the index.
\end{abstract}

Keywords: The Travel and Tourism Competitiveness Index, Quantile regression, Tourism.

JEL Classification: $\mathrm{C}_{31}, \mathrm{~L}_{3}, \mathrm{Z}_{32}$

DOI: $10.54933 / \mathrm{jmbrp}-2021-13-2-2$

Litavcová, E. \& Síč, J. (2021). Travel and tourism competitiveness index 2019 - quantile regression approach on $2^{\text {nd }}$ sub-index. Journal of Management and Business: Research and Practice, 13(2), doi: 10.54933/jmbrp-2021-13-2-2 


\section{Introduction}

Competitiveness is often a researched topic in many areas. The high competitiveness of the country in the field of tourism gives good preconditions for accelerating its performance. Porter's work is an initial work for the development of research focused on the competitiveness of tourism destinations (Porter, 1980; Porter, 1990). Tourism destination competitiveness is a multidimensional concept that is widely studied in the academic literature, but multiple factors make its measurement a difficult task (Salinas Fernandéz et al, 2020). Due to the reason that tourism is primarily a service-driven industry, tourism researchers had to adjust definitions, develop new models, and identify factors that would apply to the tourism industry (Cronjé \& du Plessis, 2020). The Travel \& Tourism Competitiveness Index (TTCI) is one of the most popular synthetic indicators worldwide developed by the WEF (2007). This index is published in odd-numbered years through WEF-TTC reports, since 2015 in a uniform methodology. According to the preface of Menon and Wolf of WEF-TTC report 2019 (Calderwood \& Soshkin, 2019), the Travel \& Tourism Competitiveness Report provides a valuable tool for policymakers, companies, and complementary sectors to understand and anticipate emerging trends and risks in global travel and tourism, adapt their policies and practices, and accelerate new models that ensure the longevity of this important sector. By allowing cross-country comparison and benchmarking countries' progress on the drivers of T\&T competitiveness, it informs policies and investment decisions related to T\&T business and industry development (Calderwood \& Soshkin, 2019). For each country considered, the main travel and tourism competitiveness score is created using the four sub-indexes that make up their pillars. These pillars are made up of other sub-pillars. The score is ultimately the basis for determining the ranking of countries. According to the WEF-TTC report 2017 of Crotti and Misrahi (2017), the five pillars of the Enabling Environment sub-index capture the general settings needed to operate in the country; the T\&T Policy and Enabling Conditions sub-index, which captures specific policies or strategic aspects that impact the T\&T industry more directly, consists of four pillars; three pillars of sub-index Infrastructure captures the availability and quality of physical infrastructure in a country; two pillars of Natural and Cultural Resources captures the main reasons to travel (Crotti \& Misrahi, 2017).

The aim of this paper is to solve a question, how the 2nd sub-index The T\&T Policy and Enabling Conditions with its four pillars influence and relate to the overall score and overall ranking among investigated countries. The main aim is from a methodological point of view, to answer this question using quantile regression and finally compare this result with OLS.

This article is arranged as follows. The following section after brief Theoretical background presents the data and variables used in the empirical application and the quantile regression method used. The next section presents the results. In the last section, the article is concluded.

\section{Theoretical background}

Current literature covers a wide range of research on competitiveness subject. Tourism destination competitiveness is a complex multidimensional concept, which was studied for example in Cucculelli and Goffi (2016), Andrades and Dimanche (2017), and Porto et al (2019). An impressive review of the literature on the competitiveness of destinations by Cronjé and du Plessis (2020) shows the widespread interest of researchers in the field of tourism research in recent decades. T\&T Competitiveness Report has been published by WEF eight times up to the year 2020 but the composition of the index has been changed several times over the years. It is possible to find publications that are aimed at improving the methodology of tourism competitiveness indicators, for example, Croes and Kubickova (2013), Mihalic (2016), Evans (2016). Salinas Fernandéz et al (2020) used all of the simple variables included in the 2017 Travel \& Tourism Competitiveness Index, proposing a new methodology for the construction of this synthetic index, which solves the problems of aggregation of variables expressed in different measures, arbitrary weighting and duplicity of information. Luštický and Štumpf (2021) focus on general models of destination competitiveness and, using the Analytic Hierarchy Process proposed model of system dynamics which allows depicting the complexity of relations among the factors of competitiveness in greater depth, to cover more relations and their causalities, and to reveal the leverage points indicating the most promising areas of cooperation. Some authors examine relationships between selected indicators of T\&T Competitiveness Index, for example, Cirstea (2014), Litavcová et al (2019), and Litavcová and Vašničová (2019). Using quantile regression, Litavcová et al (2019) studied the relationship between $1^{\text {st }}$ sub-index Enabling Environment and overall TTCI and ranking among 136 countries on previous data of TTCI from 2017. In Litavcová and Vašaničová (2019), 
the relationship of 13 other TTCI indices from 2017 to the Business Environment pillar, which is one of the five sub-pillars of the Enabling Environment pillar, was investigated using regression quantiles and lasso estimates for modeling. Nexus between TC and tourism performance can be found in Bazargani and Kilic (2021), Marti and Puertas (2017), Hanafiah and Zulkifly (2019). Bazargani and Kilic (2021) using three-step least-squares data estimation techniques have shown that tourism competitiveness is the main driver of the tourism flows and tourism contribution to GDP for all regions and income groups of countries across the world.

In some cases, data of the T\&T Competitiveness Index was used for the other analysis (Zhang et al, 2011). Attention is currently being paid to studying the impact of the pandemic on various areas of the tourism sector, including competitiveness as can be seen for example in Santos, Oliviera, and Aldrighi (2021). Altinay and Kozak (2021) use chaos theory in order to evaluate the implications of the COVID-19 pandemic for destination competitiveness.

\section{Data and methodology}

\section{Data}

The Travel and Tourism (T\&T) Competitiveness Index can be considered a quality and strategic means of assessing a country's position. According to the methodology of its creation valid for 2019, the main index was divided into 4 sub-indexes, which together consisted of 14 pillars. The pillars are created on the basis of 90 individual indicators. Composition of the T\&T Competitiveness Index in 2019 presents Table 1 .

\section{Table 1: Composition of T\&T Competitiveness Index in 2019}

\begin{tabular}{lll}
\hline Sub-index & & Pillars \\
\hline & 1. & Business Environment (BE) \\
Sub-index I. & 2. & Safety and Security (SS) \\
Enabling Environment & 3. & Health and Hygiene (HH) \\
& 4. & Human Resources and Labour Market (HRL) \\
& 5. & ICT Readiness (ICT)
\end{tabular}
6. $\quad$ Prioritization of Travel and Tourism (TT)
7. International Openness (IO)
8. Price Competitiveness (PC)
9. Environmental Sustainability (ES)

Sub-index II.

T\&T Policy and Enabling Conditions

$\begin{array}{lll} & \text { 10. } & \text { Air Transport Infrastructure (ATI) } \\ \text { Sub-index III. } & 11 . & \text { Ground and Port Infrastructure (GPI) } \\ \text { Infrastructure } & 12 . & \text { Tourist Service Infrastructure (TSI) }\end{array}$

Sub-index IV.

Natural and Cultural Resources
13. Natural Resources (NR)

14. Cultural Resources and Business Travel (CRB)

Source: own processing according to Calderwood and Soshkin, 2019.

Pillars $1^{\text {st }}$ to $5^{\text {th }}$ of the Enabling Environment sub-index in Table 1 are closely linked to economic growth. The next four pillars $6^{\text {th }}-9^{\text {th }}$ of the T\&T Policy and Enabling Conditions sub-index can direct measure of observable T\&T policies (pillar Prioritization of Travel and Tourism), which can directly impact tourists' decision to select a destination (pillars International Openness, Price Competitiveness) and which indicates to what extent natural capital is being conserved (Environmental Sustainability). The following three pillars $10^{\text {th }}-12^{\text {th }}$ assess the connectivity and hospitality infrastructure and enable policy makers to provide accurate information. The last two pillars $13^{\text {th }}-14^{\text {th }}$ represent natural and cultural resources and can be the main reason for visiting the country. The methodology of index creation in 2019 was the same as in 2017. The pillars in Table 1 were similarly described in our previous works Litavcová et al (2019), and Litavcová and Vašaničová (2019), citing Crotti and Misrahi (2017).

Our dataset consists of values of the Travel and Tourism Competitiveness Index (TTCI) and its pillars among 140 economies from the year 2019. The question is, how much each pillar of the second 
sub-index contributes to the overall index, and to the ranking in 140 countries. This article aims to answer that question by using quantile regression.

In this work, we focus on the second sub-index, which is described here according of Calderwood and Soshkin (2019). Sub-index T\&T Policy and Enabling Conditions are composed of four pillars. The pillar Prioritization of Travel and Tourism consists of 6 indicators that cover the extent to which the government favors the T\&T sector. The stability of government policy can affect the sector's ability to attract further private investment. This pillar also includes measures of government spending, the effectiveness of marketing campaigns and country branding, and the completeness and timeliness of providing T\&T data to international organizations, as this indicates the importance that a country assigns to its T\&T sector. The pillar International Openness consists of 3 indicators and describes the degree of openness and travel facilitation. Components measured in this pillar include the openness of the bilateral air service agreements which the government has entered, which impacts the availability of air connections to the country, and the number of regional trade agreements in force, which proxies the extent to which it is possible to provide world-class tourism services. The pillar Price Competitiveness consists of 4 indicators such as airfare ticket taxes and airport charges, which can make flight tickets much more expensive; the relative cost of hotel accommodation; the cost of living, proxied by purchasing power parity; and fuel price costs, which directly influence the cost of travel. The pillar Environmental Sustainability consists of 10 indicators that cover policies and factors enhancing environmental sustainability. These include policy indicators such as the rigor and enforcement of government environmental regulations and variables assessing the state of water, forest resources, and marine life, and the extent to which the T\&T industry is developed in a sustainable manner (more in Calderwood and Soshkin (2019)).

\section{Methodology}

The effect of a change in the TTCI score and the TTCI rank of the country among 140 countries depending on the four pillars of T\&T Policy and Enabling Conditions would be tested by using the ordinary least squares method, or by using a more complex generalized linear model. Our good experience with quantile regression so far (in the context of TTCI 2017 in Litavcová et al (2019), for example) is the impetus for the decision to use it again. We used quantile regression also in other contexts, for example in the context of M\&A with interesting results in Litavcová, Hečková, and Chapčáková (2016) and in Litavcová, Hečková, and Chapčáková (2017).

The response and all the regressors are continuous variables without missing values, in our data of TTCI 2019. However, outliers occur in 4 variables. When using OLS, the collinearity diagnostics confirm that there are serious problems with multicollinearity. Several eigenvalues are close to zero, indicating that the predictors are highly intercorrelated and that small changes in the data values may lead to large changes in the estimates of the coefficients. The condition indices are computed as the square roots of the ratios of the largest eigenvalue of $X^{T} X$ to each successive eigenvalue. One of these indices is larger than 30, suggesting a serious problem with collinearity (Rawlings, Pantula, and Dickey, 1998). Thus, other methods should be used (see Jurczyk (2012), Kalina and Peštová (2017)).

As Agresti (2015) explains, the simple ordinary least squares method describes the conditional mean of the response variable as a linear function of the explanatory variable. Quantile regression models quantiles of a response variable as a function of explanatory variables. This method can be less severely affected by outliers than is ordinary least squares. When the response conditional distributions are highly skewed with possibly highly non-constant variance, the method can describe the relationship better than a simple normal model with constant variance. Quantile regression model fitting minimizes of a weighted sum of absolute residuals, formulated as a linear programming problem. However, when the normal linear model truly holds, the least-squares estimators are much more efficient (Agresti 2015, in Litavcová, Hečková, and Chapčáková, 2016).

The OLS model estimates the constant effects of the independent variables on the conditional mean of the dependent variable and assumes a normal distribution of errors with constant variance. As stated in Koenker (2005), quantile regression is a statistical technique intended to estimate, and conduct inference about, conditional quantile functions. Just as classical linear regression methods based on minimizing sums of squared residuals enable one to estimate models for conditional mean functions, quantile regression methods offer a mechanism for estimating models for the conditional median function, and the full range of other conditional quantile functions (Koenker, 2005).

Quantile regression models were initially proposed by Koenker and Bassett (1978) as a method of robust regression that would account for the non-normal distribution of error terms and as a test for heteroskedastic error terms (Koenker, 2005). At the heart of the optimization problem is the minimization of asymmetrically weighted absolute residuals. By asymmetrically weighted residuals, 
they mean assigning different weights to positive and negative residuals (Britt, 2009), (Fenske, 2012). This results in the minimization equation for conditional quantiles

$$
\min _{\xi \in R} \sum_{i=1}^{n} \rho_{\tau}\left(y_{i}-\xi(x, \beta)\right),
$$

where $\rho($.$) is the absolute value function that gives the \tau$-th sample quantile, $y_{i}$ is the observed value of the dependent variable, and $\xi(x, \beta)$ is the predicted value in the form of parametric function.

\section{Results}

Table 2 shows the coefficients of the TTC score and the TTCI rank among 140 countries as a dependent variable, which were estimated at the $15^{\text {th }}, 20^{\text {th }}, 25^{\text {th }}, 30^{\text {th }}, 40^{\text {th }}, 50^{\text {th }}, 60^{\text {th }}, 70^{\text {th }}, 75^{\text {th }}, 80^{\text {th }}$, and $85^{\text {th }}$ quantile levels (taus) using multiple quantile regression on four pillars of the second sub-index. Robust bootstrap estimates of standard errors according to Koenker and Hallock (2001) were made and significance tests were based on them. As can be seen from Table 2, the quantile regression provided us with a more complete and detailed statistical analysis of the stochastic relationships between the random variables examined. For comparison, the coefficients of the OLS model are in the last line.

It is clear from Table 2 that the first two pillars Prioritization of Travel and Tourism and International Openness in this presented multiple quantile regression model influence significantly all the investigated quantile levels of both examined dependent variables - overall TTC score and TTCI rank. On the contrary, the third pillar Price Competitiveness has no effect on any of the quantile levels of both dependent variables. This unexpected result is because not all 14 pillars were included in the considered model as a set of independent variables. The Environmental Sustainability variable affects the different quantile levels of the TTC score variable differently. As quantile levels of TTC score increase, the effect of Environmental Sustainability decrease and cease to be significant at the 6oth percentile. However, a similar effect in the opposite direction is achieved with the variable TTCI rank. The higher its quantile level, the more it is affected by the Environmental Sustainability variable. Significance begins with the median of the dependent variable TTCI rank.

Table 2 Estimated coefficients of Business Environment as a dependent variable - results of multiple quantile regression

\begin{tabular}{|c|c|c|c|c|c|c|c|c|}
\hline \multirow[b]{2}{*}{ tau } & \multicolumn{4}{|c|}{$1^{\text {st }}$ model - dependent: TTCI Rank } & \multicolumn{4}{|c|}{$2^{\text {nd }}$ model - dependent: TTC Score } \\
\hline & TT & IO & PC & ES & TT & IO & PC & ES \\
\hline 0,15 & $-18.539 \mathrm{~d}$ & $-19 \cdot 373^{\mathrm{d}}$ & $7 \cdot 998$ & -3.148 & $0.292 \mathrm{~d}$ & $0.262 \mathrm{c}$ & 0.015 & $0.473^{\mathrm{d}}$ \\
\hline 0,20 & $-18.416 \mathrm{~d}$ & $-19.759 d$ & $6.963^{\mathrm{a}}$ & -4.059 & $0.281 \mathrm{~d}$ & $0.319 \mathrm{~d}$ & 0.067 & $0.475^{\mathrm{d}}$ \\
\hline 0,25 & $-17.914^{\mathrm{d}}$ & $-20.466 \mathrm{~d}$ & 4.694 & -6.921 & $0.295^{\mathrm{d}}$ & $0.301^{d}$ & 0.108 & $0.478 \mathrm{~d}$ \\
\hline 0,30 & $-20.984^{d}$ & $-21.013^{d}$ & 1.590 & -7.035 & $0.276 \mathrm{~d}$ & $0.319^{d}$ & 0.093 & $0.436 \mathrm{~d}$ \\
\hline 0,40 & $-13 \cdot 569 d$ & $-25.860 \mathrm{~d}$ & 2.252 & $-13.134^{a}$ & $0.260 \mathrm{~d}$ & $0.324^{\mathrm{d}}$ & 0.072 & $0.35^{2 \mathrm{~d}}$ \\
\hline 0,50 & $-15.826 \mathrm{~d}$ & $-20.836 d$ & 1.194 & $-17.110 c$ & $0.257^{d}$ & $0.321 \mathrm{~d}$ & 0.004 & $0.297^{c}$ \\
\hline 0,60 & $-13.921^{d}$ & $-19.581^{d}$ & -3.952 & $-24.982^{d}$ & $0.232^{d}$ & $0.378 \mathrm{~d}$ & -0.059 & $0.241^{\mathrm{a}}$ \\
\hline 0,70 & $-15 \cdot 353^{\mathrm{d}}$ & $-19.264^{\mathrm{d}}$ & -2.953 & $-26.681^{d}$ & $0.345^{\mathrm{d}}$ & $0.35^{8 d}$ & -0.040 & 0.132 \\
\hline 0,75 & $-17 \cdot 398 d$ & $-17 \cdot 312^{\mathrm{d}}$ & -2.802 & $-28.516 \mathrm{~d}$ & $0.368 d$ & $0.336 \mathrm{~d}$ & -0.129 & 0.073 \\
\hline 0,80 & $-15.215^{\mathrm{d}}$ & $-20.068 d$ & -0.666 & $-28.278 d$ & $0.377^{c}$ & $0.334^{c}$ & -0.153 & 0.068 \\
\hline 0,85 & $-17.777^{d}$ & $-14.016 c$ & 1.769 & $-29.789 \mathrm{~d}$ & $0.414^{c}$ & $0.297 \mathrm{c}$ & -0.162 & 0.075 \\
\hline OLS & $-16.999^{\mathrm{d}}$ & $-19.207^{\mathrm{d}}$ & 1.754 & $-16.291^{\mathrm{d}}$ & $0.299^{\mathrm{d}}$ & $0.329^{d}$ & 0.057 & $0.271^{\mathrm{c}}$ \\
\hline
\end{tabular}

Note: " $a$ ", "b", "c", "d" denotes $10 \%, 5 \%, 1 \%$, and $0.1 \%$ significance level; the abbreviations at the top of the table are explained on page 2.

The following figures (Figure 1, Figure 2) provide a more detailed and moderate overview of the examined dependencies. The images allow a fine view of the studied dependencies and allow a comparison with OLS.

The OLS estimate of the average value of the dependent variable is shown by a red line, with his $95 \%$ confidence interval, respectively. 


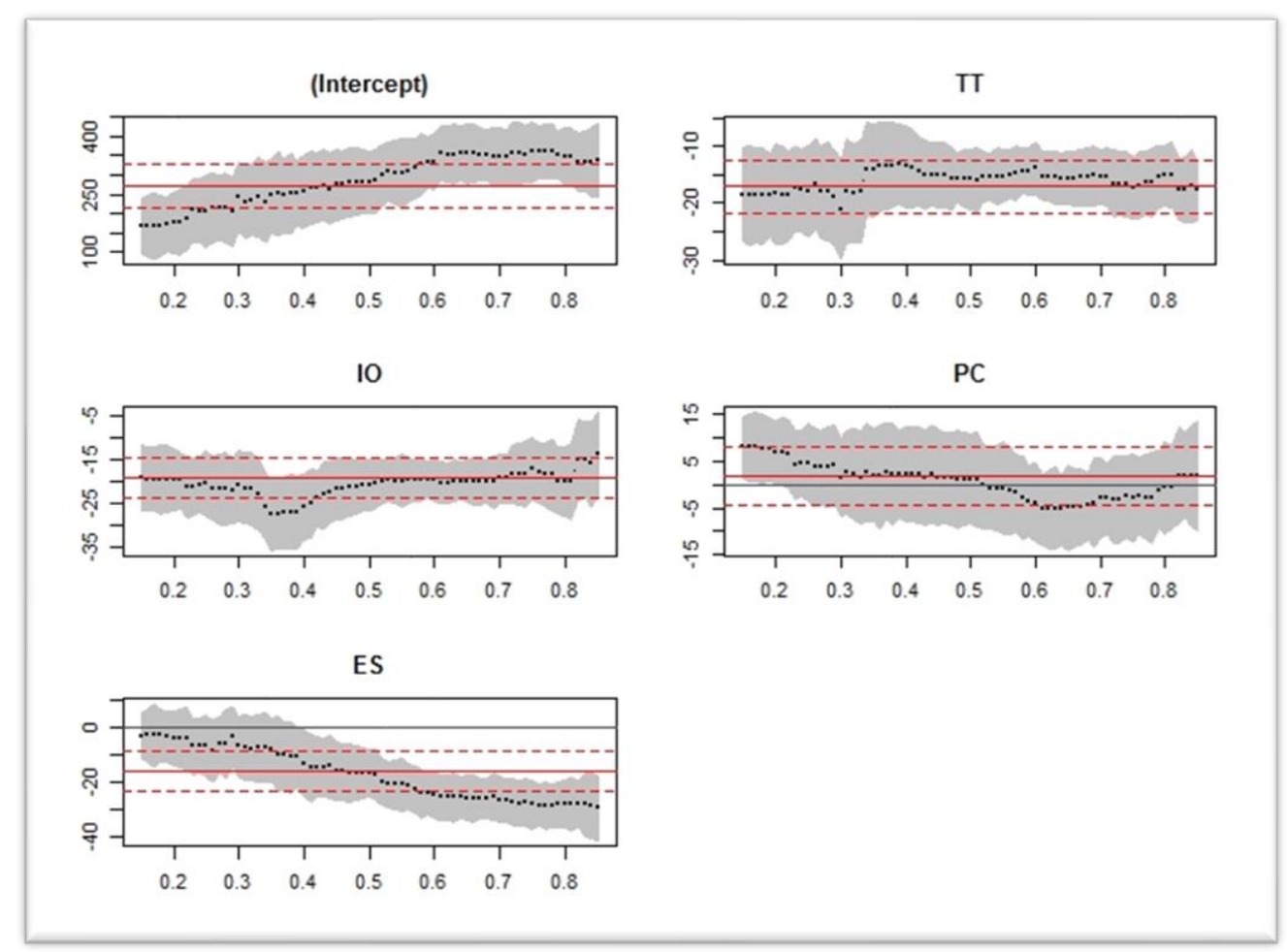

Figure 1 Comparison of estimated parameters at various quantile levels as a result of quantile regression with dependent variable TTC Rank.

Note: CIs are based on bootstrap estimates of standard errors.

Source: own calculation in $R$.

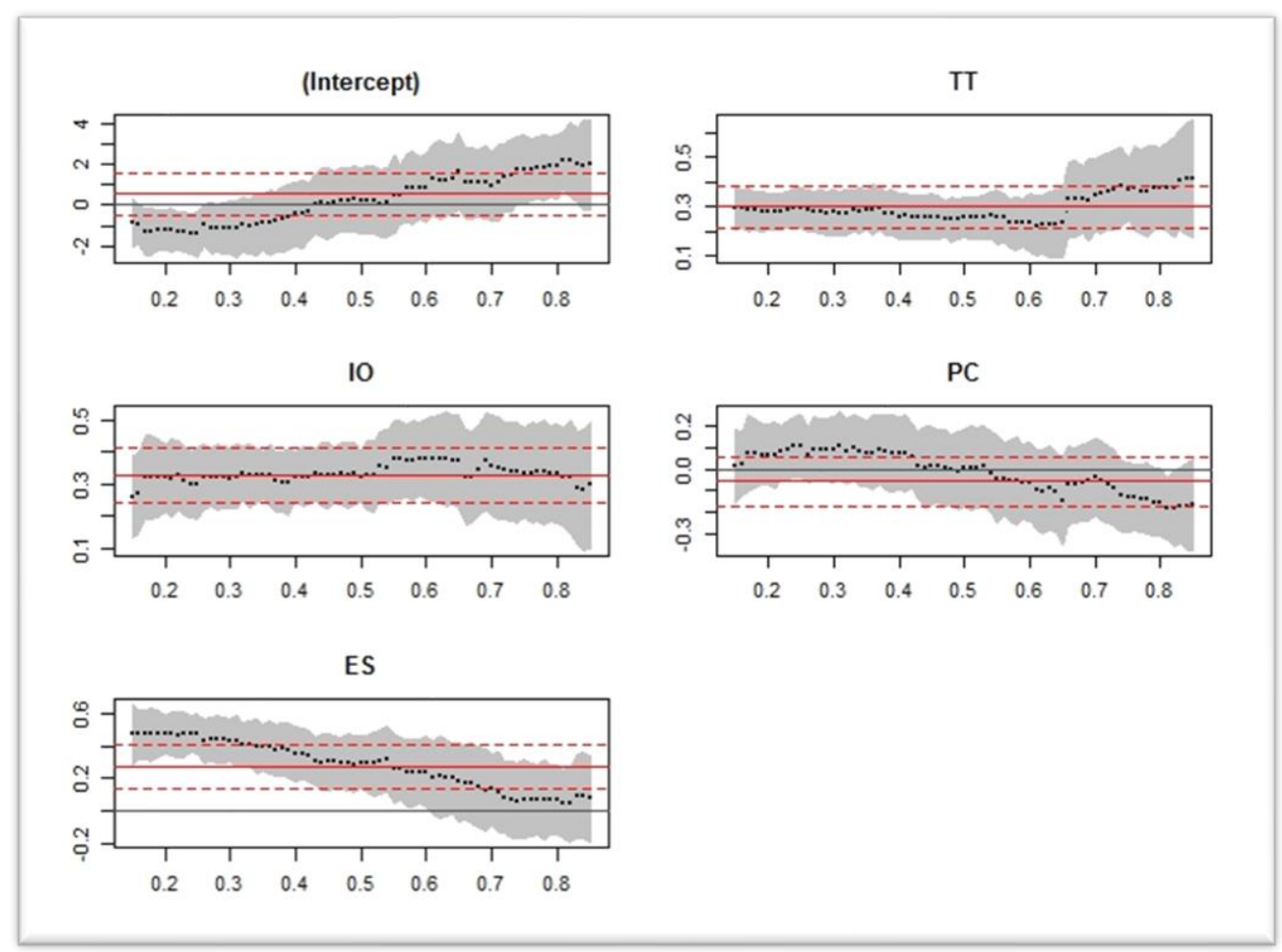

Figure 2 Comparison of estimated parameters at various quantile levels as a result of quantile regression with dependent variable TTC Score.

Note: CIs are based on bootstrap estimates of standard errors.

Source: own calculation in $R$. 
It is clear from Figure 1 that the very low quantile levels of the dependent variable TTC rank are significantly affected by the variable Price Competitiveness, but the OLS model does not say so. The choice of the quantile regression model over the OLS model is fully justified in the case of the considered multidimensional model in terms of the Environmental Sustainability variable - Figures 1 and 2 show that the estimate of the mean value differs from the estimate of the quantile level of both dependent variables TTC score and TTCI rank at most their quantile levels. The OLS model considers the influence of the Environmental Sustainability variable to be significant, the quantile regression model only at certain quantile levels.

\section{Discussion}

To reveal the relationship between the TTC index and ranking among 140 countries on four pillars of the $2^{\text {nd }}$ sub-index of TTCI the multiple quantile regression analysis was used. The expected significant impact of the Price Competitiveness pillar has not been confirmed in this model. Therefore, we also checked the overall model not listed here, where we took all 14 pillars. There, the importance of the Price Competitiveness pillar has already been proven. Significancy of pillars Prioritization of Travel and Tourism and International Openness was revealed in all considered quantile levels. This makes the result no different from OLS and there is reason to accept the result of OLS taking into account that according to Agresti (2015) the normal linear model truly holds. On the contrary, a result that speaks of the significancy of the Environmental Sustainability pillar only at certain quantile levels gives a good reason to derive managerial implications based on quantile regression results. These results do not differ from our results in previous work (Litavcová et al, 2019) that emerged from the analysis of data TTCI from previous 2017 report.

\section{Conclusion}

In this paper, the relationship between selected four pillars of the Travel and Tourism Competitiveness Index (TTCI) in its second sub-index and the overall variable TTC score (and TTCI rank too) among 140 countries was studied. The data of TTCI 2019 was studied. Quantile regression allowed us to examine this relationship in a broader context. The aim of this contribution was to examine the multivariate relationship between response variable, which is the overall TTC score (and TTCI rank) among 140 countries and selected four of all 14 continuous predictors, e. g. pillars of second sub-index "T\&T Policy and Enabling Conditions". We recorded several findings from the results of the analyses. First, the most important pillars in the investigated model are Prioritization of Travel and Tourism, and International Openness. Second, on the contrary, the pillar Price Competitiveness has almost no effect on the overall TTCI score or TTCI rank in the considered model. Third, a comparison of the results of the multiple quantile regression analysis with the ordinary least squares showed that the results of the above methods differ significantly for pillar Environmental Sustainability. The estimate of the mean value differs from the estimate of the quantile level of both dependent variables TTC score and TTCI rank at most their quantile levels. The OLS model considers the influence of the Environmental Sustainability pillar to be significant, the quantile regression model only at certain quantile levels. On the lower quantile levels, this pillar does not significantly affect the ranking while at higher quantile levels it does. On the contrary, it affects the overall TTCI score in the opposite way. Another reason for using quantile regression is justified by the restrictive assumptions of OLS that it does not require. To conclude, these results may be helpful for a deeper understanding of the relationship between the overall TTC score (and TTCI rank) among 140 countries and its continuous predictors from the second subindex of TTCI. This paper contributes to the existing literature connected with tourism competitiveness. It can be useful in revealing hidden multidimensional relationships between variables considered at different quantile levels. The obtained results can be a motivation for further in-depth analysis and ultimately for further improvement of the methods used in compiling the index.

Tourism destination comprises a highly competitive and complex market (Luštický and Štumpf, 2021). TTCI is a multidimensional concept that is complex and makes sense to study it in more depth. It has been improved several times since its first release in 2007. In 2015, it underwent the last significant methodological change. In this article, the latest pre-pandemic version from 2019 is studied. The tourism-related sectors have been among the most affected by the pandemic, notably air travel, due to the perception that they could be a conduit to the virus's spread (Santos, Oliviera, and Aldrighi, 2021). It is possible to assume that other variables can therefore be added to the TT concept, the issue of health safety of travel, for example. Altinay and Kozak (2021) proposed in this context the butterfly 
competitiveness model which suggests that as destinations transform themselves to adapt to the unpredictable consequences of COVID-19 and strive to remain competitive in the tourism market, they need to demonstrate health leadership. It will therefore be interesting to study data from 2021 on how the models tested so far will behave. According to WTTC news (15 October 2021) „In a slower than expected recovery GDP contribution will only increase by less than one third. Nearly 19 million Travel \& Tourism jobs are in the balance in 2021“. In-depth statistical analysis of variables for each area, also for destination competitiveness in tourism, the results can help policy makers set parameters to address the consequences of the pandemic and to achieve increased competitiveness.

\section{Acknowledgment}

This paper was supported by the Slovak Research and Development Agency under the contract no. APVV-17-0166.

\section{References}

Agresti, A. (2015). Foundations of Linear and Generalized Linear Models. Hoboken, New Jersey: John Wiley \& Sons.

Altinay, L. \& Kozak, M. (2021). Revisiting destination competitiveness through chaos theory: The butterfly competitiveness model. Journal of Hospitality and Tourism Management 49, 331-340.

Britt, C.L., 2009. Modeling the distribution of sentence length decisions under a guidelines system: An application of quantile regression models. Journal of Quantitative Criminology, 25(4), 341-370.

Andrades, L. \& Dimanche, F. (2017). Destination competitiveness and tourism development in Russia: Issues and challenges. Tourism Management, 62, 360-376.

Bazargani, R.H.Z. \& Kilic, H. (2021). Tourism competitiveness and tourism sector performance: Empirical insights from new data. Journal of Hospitality and Tourism Management, 46, 73-82.

Calderwood, L.U. \& Soshkin, M. (2019). The Travel \& Tourism Competitiveness Report 2019. Travel and Tourism at a Tipping Point. Geneva: World Economic Forum.

Cirstea, S.D. (2014). Travel \& Tourism Competitiveness: A Study of World's Top Economic Competitive Countries. Procedia Economics and Finance, 15, 1273-1280.

Croes, R. \& Kubickova, M. (2013). From potential to ability to compete: Towards a performance-based tourism competitiveness index. Journal of Destination Marketing and Management, 2(3), 146154 .

Cronjé, D.F. \& du Plesis, E. (2020). A review on tourism destination competitiveness. Journal of Hospitality and Tourism Management, 45, pp. 256-265.

Crotti, R. \& Misrahi, T. (2017). The Travel \& Tourism Competitiveness Report 2017: Paving the way for a more sustainable and inclusive future. Geneva: The World Economic Forum.

Cucculelli, M. \& Goffi, G. (2016). Does sustainability enhance tourism destination competitiveness? Evidence from Italian destinations of excellence. Journal of Cleaner Production, 111(Part B), $370-382$.

Evans, N.G. (2016). Sustainable competitive advantage in tourism organizations: A strategic model applying service dominant logic and tourism's defining characteristics. Tourism Management Perspectives, 18, 14-25.

Fenske, N. (2012). Structured additive quantile regression with applications to modelling undernutrition and obesity of children. Dissertation thesis. Munchen.

Hanafiah, M.H. \& Zulkifly, M.I. 2019. Tourism destination competitiveness and tourism performance. Competitiveness Review: An International Business Journal, 29(5), 592-621.

Jurczyk, T. (2012). Outlier Detection under Multicollinearity. Journal of Statistical Computation and Simulation, 82 (2), 261-278.

Kalina, J. \& Peštová, B. (2017). Exact Inference in Robust Econometrics under Heteroscedasticity. Proceedings of 11th International Days of Statistics and Economics MSED 2017 (pp. 636-645), Prague, Czech Republic.

Koenker, R. \& Bassett, G. (1978). Regression Quantiles. Econometrica, 46 (1), 33-50.

Koenker, R. \& Hallock, K.F. (2001). Quantile regression. The Journal of Economic Perspectives, 15 (4), 43-56.

Koenker, R. (2005). Quantile regression. Cambridge University Press, New York

Litavcová, E., Hečková, J., \& Chapčáková, A. (2016). Cross-border Mergers and Acquisitions in terms of Quantile Regression. Proceedings of the Management 2016 : international business and 
management, domestic particularities and emerging markets in the light of research. Prešov: Bookman, s.r.o. for Faculty of Management. p.628-634.

Litavcová, E., Hečková, J., \& Chapčáková, A. (2017). Cross-border mergers and acquisitions as efficient management tool of capital allocation within European area. Polish Journal of Management Studies, 16(1), 94-104.

Litavcová, E., Vašaničová, P., Jenčová, S., \& Košíková, M. (2019). Travel and Tourism Competitiveness Index 2017 - Quantile Regression Approach of Enabling Environment Pillars. Proceedings of the $13^{\text {th }}$ International Conference on Strategic Management and its Support by Information Systems SMSIS 2019, (pp. 187-195), Ostrava, Czech Republic.

Litavcová, E., Vašaničová, P. (2019). Business environment and its relations within travel and tourism competitiveness index. MME 2019 - Proceedings of the $37^{\text {th }}$ International Conference on Mathematical methods in economics, (pp. 487-492), České Budějovice, Czech Republic.

Luštický, M. \& Štumpf, P. (2021). Leverage points of tourism destination competitiveness dynamics. Tourism Management Perspectives, 38, 100792.

Marti, L. \& Puertas, R. (2017). Determinants of tourist arrivals in European Mediterranean countries: Analysis of competitiveness. European Journal of Tourism Research, 15, 131.

Mihalic, T. (2016). Sustainable-responsible tourism discourse. Towards 'responsustable' tourism. Journal of Cleaner Production, 111(Part B), 461-470.

Porter, M.E. (1980). Industry structure and competitive strategy: Keys to profitability. Financial Analysts Journal, 36(4), 31-41.

Porter, M.E. (1990). The competitive advantage of nations. Harvard Business Review, 68(2), 73-93.

Porto, N., Rucci, A.,C., Darcy, S., Garbero, N., \& Almond, B. (2019). Critical elements in accessible tourism for destination competitiveness and comparison: Principal component analysis from Oceania and South America. Tourism Management, 75, 169-185.

Rawlings, J.O., Pantula, S.G., \& Dickey, D.A. (1998). Applied Regression Analysis: A Research Tool, Second Edition. New York: Springer-Verlag, Inc.

Salinas Fernandéz, J.A., Azevedo, S.P., Martín, M.J.M., \& Martín, R.J.A. (2020). Determinants of tourism destination competitiveness in the countries most visited by international tourists: Proposal of a synthetic index. Tourism Management Perspectives, 33, 100582.

Santos, L.J., Oliviera, A.V.M., \& Aldrighi, D.M. (2021). Testing the differentiated impact of the COVID19 pandemic on air travel demand considering social inclusion. Journal of Air Transport Management, 94 (2021) 102082.

Zhang, H., Gu, C., Gu, L., \& Zhang, Y. (2011). The evaluation of tourism destination competitiveness by topsis \& information entropy: A case in the Yangtze River Delta of China. Tourism Management, $32,443-451$.

WEF. (2007). The travel \& tourism competitiveness report 2007: Furthering the process of economic development. Geneva: The World Economic Forum.

WEF. (2019). The Travel \& Tourism Competitiveness Report 2019: Travel and Tourism at a Tipping Point. Geneva: The World Economic Forum.

World Travel \& Tourism Council (WTTC). (2021). [viewed 15 October 2021]. Available from: https://wttc.org/News-Article/WTTC-research-reveals-Travel-and-Tourism-slow-recoveryis-hitting-jobs-and-growth-worldwide 